\title{
A rare cause of postpartum acute hyponatremia
}

Ilan Rahmani Tzvi-Ran, Judith Olchowski, Merav Fraenkel, Asher Bashiri and Leonid Barski

Department of Internal Medicine F, Soroka University Medical Center, Beer Sheva, Israel
Correspondence should be addressed to I Rahmani Tzvi-Ran Email

Rahmani.ilan@gmail.com

\section{Summary}

A previously healthy 24-year-old female underwent an emergent caesarean section without a major bleeding described. During the first post-operative days (POD) she complained of fatigue, headache and a failure to lactate with no specific and conclusive findings on head CT. On the following days, fever rose with a suspicion of an obstetric surgery-related infection, again with no evidence to support the diagnosis. On POD5 a new-onset hyponatremia was documented. The urine analysis suggested SIADH, and following a treatment failure, further investigation was performed and demonstrated both central hypothyroidism and adrenal insufficiency. The patient was immediately treated with hydrocortisone followed by levothyroxine with a rapid resolution of symptoms and hyponatremia. Further laboratory investigation demonstrated anterior hypopituitarism. The main differential diagnosis was Sheehan's syndrome vs lymphocytic hypophysitis. Brain MRI was performed as soon as it was available and findings consistent with Sheehan's syndrome confirmed the diagnosis. Lifelong hormonal replacement therapy was initiated. Further complaints on polyuria and polydipsia have led to a water deprivation testing and the diagnosis of partial central insipidus and appropriate treatment with DDAVP.

\section{Learning points:}

- Sheehan's syndrome can occur, though rarely, without an obvious major post-partum hemorrhage.

- The syndrome may resemble lymphocytic hypophysitis clinically and imaging studies may be crucial in order to differentiate both conditions.

- Hypopituitarism presentation may be variable and depends on the specific hormone deficit.

- Euvolemic hyponatremia workup must include thyroid function test and 08:00 AM cortisol levels.

\section{Background}

Sheehan's syndrome was first described by the British pathologist Harold Leeming Sheehan in 1937 as postpartum pituitary necrosis, most often caused by significant postpartum hemorrhage though as in our case not always a major bleeding is described. Sheehan's syndrome is a relatively rare condition in developed countries compared to developing countries and is therefore not infrequently overlooked, especially in the absence of a major postpartum hemorrhage $(1,2)$. The syndrome may present with an inability to lactate postpartum, but not infrequently, it may be diagnosed years after the inciting delivery with variable pituitary hormonal deficiencies (1, 3). Many nonspecific manifestations are possible depending on individual's hormonal losses which may vary, though failure to lactate and amenorrhea are relatively common $(1,2)$. Acute hyponatremia as the main presenting problem is less common. It has been described in few case reports following a significant postpartum hemorrhage and the development of a hemorrhagic shock (Table 1). The main differential diagnosis is between lymphocytic hypophysitis and Sheehan's syndrome (4). There is a significant clinical overlap between the two conditions 
Table 1 Comparison of Sheehan's syndrome case reports resulting in acute hyponatremia.

\begin{tabular}{|c|c|c|c|}
\hline First author & Blood loss $(L)$ & $\begin{array}{l}\text { Shock } \\
\text { (yes/no) }\end{array}$ & $\begin{array}{l}\text { Clinical } \\
\text { manifestation }\end{array}$ \\
\hline Putterman (10) & 2 & Yes & Paresthesia \\
\hline Boulanger (11) & $\begin{array}{l}\text { Not } \\
\text { described }\end{array}$ & $\begin{array}{l}\text { Not } \\
\text { described }\end{array}$ & Asthenia \\
\hline Schrager (12) & $\begin{array}{l}\text { Not } \\
\text { described } \\
\text { (severe) }\end{array}$ & Yes & Fatigue \\
\hline Lust (13) & 3.2 & Yes & Headache \\
\hline Bunch (14) & Massive & Yes & Headache \\
\hline Kaplun J (15) & Massive & Yes & Headache, fever \\
\hline Anfuso (16) & 0.5 & No & $\begin{array}{l}\text { Asthenia, } \\
\text { headache }\end{array}$ \\
\hline Matsuzaki (17) & 5 & Yes & Convulsion, coma \\
\hline Current case & 1 & No & $\begin{array}{l}\text { Fever, headache, } \\
\text { fatigue }\end{array}$ \\
\hline
\end{tabular}

while MRI images of the pituitary may be very helpful in differentiating between the two conditions (1).

\section{Case presentation}

A healthy 24-year-old female G2P2, 39-week pregnant with a normal pregnancy follow-up, presented to the obstetric emergency department due to uterine contractions. Labor induction was performed due to lack of progress of labor. Fetal heart rate monitoring showed a non-reassuring fetal heart rate (NRFHR) and the patient underwent an emergent caesarean section without major bleeding $(1000 \mathrm{~mL})$. The pre-operative hemoglobin levels were $7.8 \mathrm{~g} / \mathrm{dL}$ and the post-operative level was $7.2 \mathrm{~g} / \mathrm{dL}$. On the second POD, the patient complained of severe headache, fatigue and failure to lactate. Brain CT scan demonstrated an abnormal unspecific supra-sellar mass. On POD5 the patient had fever of 39 for the first time during the admission. Empiric antibiotic therapy was initiated with a working diagnosis of endometritis due to nonspecific abdominal complaints and after chest X-ray and urinalysis were within normal range. Abdominal CT scan ruled out an abdominal abscess and other source of infection. Blood and urine cultures were negative. Simultaneously a routine biochemical investigation revealed new-onset hyponatremia $(\mathrm{Na}=124 \mathrm{mEq} / \mathrm{L}, \mathrm{POD} 2$ level was $148 \mathrm{mEq} / \mathrm{L}$, Table 2) (normal range 135-145). Urine analysis showed osmolarity of $572 \mathrm{mosmol} / \mathrm{kg}$ and a urine sodium of $149 \mathrm{mEq} / \mathrm{L}$ consistent with the syndrome of inappropriate $\mathrm{ADH}(\mathrm{SIADH})$. She was treated accordingly with fluid restriction, furosemide, salt tablets and eventually hypertonic saline. Sodium levels failed to rise, and the patient was transferred to the internal
Table 2 Patient's relevant blood tests during pregnancy and presentation.

\begin{tabular}{|c|c|c|c|c|}
\hline \multirow[b]{2}{*}{ Parameters } & \multicolumn{4}{|c|}{ Pregnancy age } \\
\hline & 8 weeks & 25 weeks & 39 weeks (POD2) & POD11 \\
\hline $\mathrm{Hb}(\mathrm{g} / \mathrm{dL})$ & 13 & 9.4 & 7.8 & 7.5 \\
\hline $\mathrm{Na}(\mathrm{mEq} / \mathrm{L})$ & 138 & - & 148 & 117 \\
\hline $\mathrm{K}(\mathrm{mEq} / \mathrm{L})$ & 4 & - & 4.1 & 5.1 \\
\hline TSH (ulU/mL) & 2.49 & 2.1 & - & 0.12 \\
\hline Free T3 (pg/mL) & - & - & - & 1.8 \\
\hline Free T4 (pg/mL) & - & - & - & 0.6 \\
\hline
\end{tabular}

medicine ward. Physical examination upon admission was prominent for weakness, lethargy and altered mental status. Blood pressure measurements were at the low end of normal range $(90 / 50 \mathrm{mmHg})$.

\section{Investigation}

Thyroid function tests were obtained and were consistent with central hypothyroidism. A complete hormonal workup demonstrated anterior hypopituitarism (Table 3); the possibility of Sheehan's syndrome and lymphocytic hypophysitis were considered and a brain MRI was ordered in order to differentiate between the two. On POD17 the patient performed a brain MRI (Figs 1 and 2) which showed a normal, non-thickened central pituitary stalk, a normal pituitary with circumferential enhancement following gadolinium injection consistent with Sheehan's syndrome. Several days following discharge the patient developed polyuria and nocturia, dehydration test was performed and was consistent with partial central DI with good response to DDAVP.

Table 3 Blood hormone levels on POD5.

\begin{tabular}{|c|c|}
\hline Hormones & Values \\
\hline $\mathrm{TSH}$ & $0.12 \mathrm{uU} / \mathrm{L}(0.39-4)$ \\
\hline FT3 & $1.8 \mathrm{pg} / \mathrm{dL}(2.3-4.2)$ \\
\hline FT4 & $0.6 \mathrm{pg} / \mathrm{dL}(0.8-1.5)$ \\
\hline Cortisol (08:00 AM) & $<0.6 \mathrm{ug} / \mathrm{dL}$ \\
\hline $\begin{array}{l}\text { Cortisol after ACTH stimulation } \\
\text { administration }\end{array}$ & $5.26 \mathrm{ug} / \mathrm{dL}$ \\
\hline Prolactin & $7 \mathrm{ng} / \mathrm{mL}(1-29)$ * \\
\hline LH & $<0.2 \mathrm{IU} / \mathrm{L}$ \\
\hline FSH & 0.4 IU/L9 \\
\hline Estradiol & $<21 \mathrm{pg} / \mathrm{mL}$ \\
\hline Growth hormone & $<0.05 \mathrm{ng} / \mathrm{mL}(0-5)$ \\
\hline IGF-1 & $75 \mu \mathrm{g} / \mathrm{L}(102-317)$ \\
\hline
\end{tabular}

*Normal range to a non-pregnant non-lactating female; "lall measurements are below minimal values regardless to the timing during the menstrual period.

$\mathrm{FSH}$, follicular-stimulating hormone; IGF-1, insulin-like growth factor 1; LH, luteinizing hormone; TSH, thyroid-stimulating hormone. 


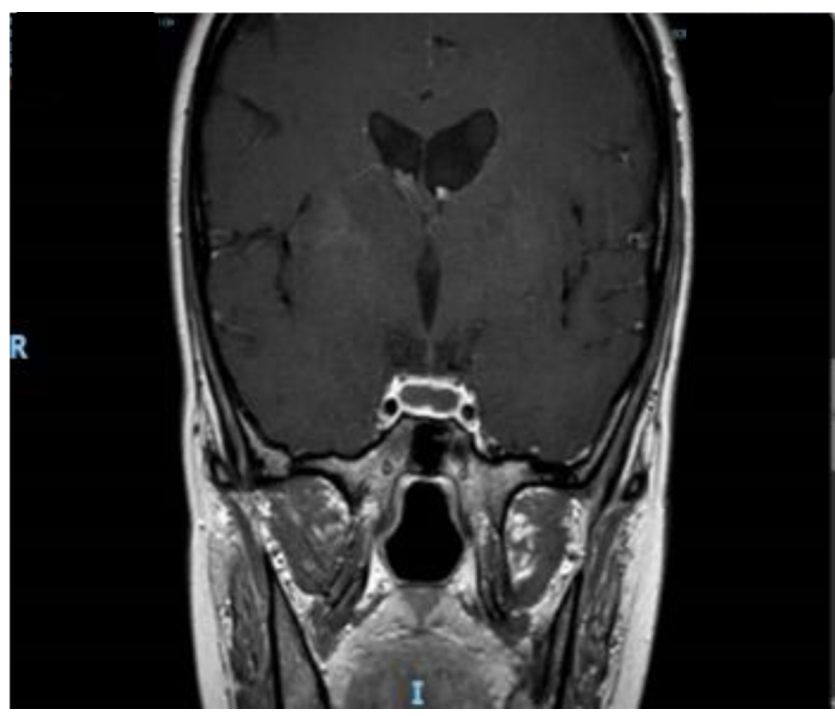

Figure 1

Patients' brain MRI.

\section{Treatment}

As soon as there were findings consistent with adrenal insufficiency, the patient was initially treated with IV hydrocortisone followed by thyroid hormone replacement which resulted in a rapid clinical and biochemical response, including reversal of hyponatremia. Until the completion of brain MRI, no additional treatment was given as there was doubt whether the diagnosis was Sheehan's syndrome or lymphocytic hypophysitis. On follow-up visits in the endocrine unit clinic, DDAVP,

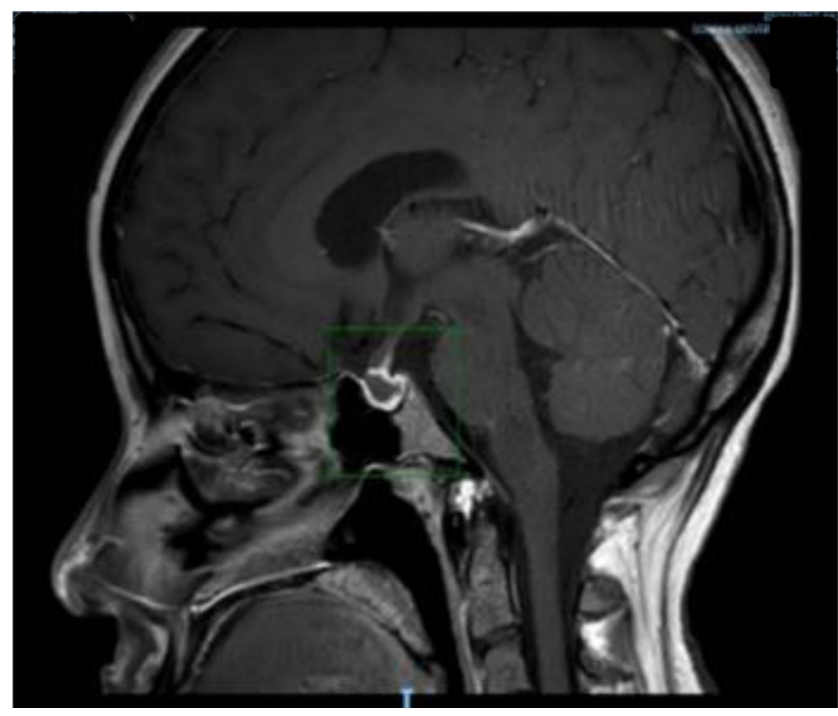

Figure 2

Patients' brain MRI. estrogen-based hormone replacement therapy and growth hormone treatment were added.

\section{Outcome and follow-up}

As described earlier, glucocorticoids and thyroid replacement therapies resulted in a rapid laboratory and clinical improvement. DDAVP treatment resulted in a good clinical response with a decrease in polyuria and nocturia. The patient is currently at our hospital's endocrinology clinic follow-up. Ten months after the inciting delivery, the patient feels well with no specific complaint. The patient will require a lifelong hormonal replacement therapy.

\section{Discussion}

The diagnosis of Sheehan's syndrome is frequently overlooked and is not infrequently made only years after the inciting delivery suggesting underdiagnosis in general, and specifically during the peri-partum period $(3,5)$. A higher index of suspicion should rise when dealing with a women from a third-world country or following a history of a home delivery where rates of peri-partum bleeding are more common $(1,2)$. However, rarely as in the current case, Sheehan's syndrome may develop without any obvious post-partum bleeding and in a developed country with modern medical care. The main differential diagnosis of Sheehan's syndrome is lymphocytic hypophysitis and both may present in the peripartum period with headache and pituitary hormonal deficiencies. The differentiation between the two conditions is primarily based on the lack or presence of a major PPH, distinctive brain MRI findings, higher rates of posterior pituitary failure and a concurrent autoimmune disease in lymphocytic hypophysitis $(1,6)$. In the current case, despite the lack of a major PPH, the diagnosis of Sheehan's syndrome was made mainly due to suggestive brain MRI findings and the lack of the typical MRI findings of hypophysitis. In addition, the lack of an additional autoimmune process supported Sheehan's syndrome, while partial central DI was diagnosed later in our patient and is not typical of Sheehan's syndrome. Nevertheless, we decided not to treat with pharmacological doses of corticosteroids, in addition to treatment of the hormonal deficiencies. Sheehan's syndrome may lead to serum sodium level abnormalities. Hypernatremia may develop in the setting of posterior pituitary necrosis and central diabetes insipidus (7). Hyponatremia is a more common manifestation and occurs when adrenal insufficiency or hypothyroidism develop as they are both 
etiologies for euvolemic hyponatremia (8). Hyponatremia, and specifically euvolemic hyponatremia is a condition of many etiologies and all must be taken into consideration as a part of the hyponatremia workup (9). When approaching a clinical condition, whatever it may be, one must always remember that common findings may be caused by rare conditions and consider an alternative diagnosis upon treatment failure.

\section{Declaration of interest}

The authors declare that there is no conflict of interest that could be perceived as prejudicing the impartiality of the research reported.

\section{Funding}

This case report did not receive any specific grant from any funding agency in the public, commercial or not-for-profit sector.

\section{Patient consent}

Written consent has been received from the patient.

\section{Author contribution statement}

Ilan Rahmani Tzvi-Ran - Main writer, literature overview. Judith Olchowsky - Internal medicine MD, was a part of the treating team. Leonid Barski Head of Internal Medicine Department F, Part of the treating team, case reviewer. Merav Fraenkel - Endocrinologist, Part of the treating team, case reviewer. Asher Bashiri - Gynecologist, case reviewer.

\section{References}

1 Zargar AH, Singh B, Laway BA, Masoodi SR, Wani AI \& Bashir MI. Epidemiologic aspects of postpartum pituitary hypofunction (Sheehan's syndrome). Fertility and Sterility 200584 523-528. (https://doi.org/10.1016/j.fertnstert.2005.02.022)

2 Diri H, Tanriverdi F, Karaca Z, Senol S, Unluhizarci K, Durak AC, Atmaca H \& Kelestimur F. Extensive investigation of 114 patients with Sheehan's syndrome: a continuing disorder. European Journal of Endocrinology 2014171 311-318. (https://doi.org/10.1530/EJE-140244

3 Banzal S, Ayoola EA \& Banzal S. Sheehan's syndrome in Saudi Arabia. International Journal of Gynaecology and Obstetrics 199966 181-182. (https://doi.org/10.1016/S0020-7292(99)00065-X]
4 Caturegli P, Newschaffer C, Olivi A, Pomper MG, Burger PC \& Rose NR. Autoimmune hypophysitis. Endocrine Reviews 200526 599-614. (https://doi.org/10.1210/er.2004-0011)

5 Dökmetaş HS, Kilicli F, Korkmaz S \& Yonem O. Characteristic features of 20 patients with Sheehan's syndrome. Gynecological Endocrinology 200622 279-283. (https://doi.org/10.1080/09513590600630504)

6 Bayram F, Keleştimur F, Oztürk F, Selçuklu A, Patiroğlu TE \& Beyhan Z. Lymphocytic hypophysitis in a patient with Graves' disease. Journal of Endocrinological Investigation 199821 193-197. (https://doi.org/10.1007/BF03347301)

7 Kan AK \& Calligerous D. A case report of Sheehan's syndrome presenting with diabetes insipidus. Australian and New Zealand Journal of Obstetrics and Gynaecology 199838 224-226. (https://doi. org/10.1111/j.1479-828X.1998.tb03009.x)

8 Huang YY, Ting MK, Hsu BR \& Tsai JS. Demonstration of reserved anterior pituitary function among patients with amenorrhea after postpartum hemorrhage. Gynecological Endocrinology 200014 99-104. (https://doi.org/10.3109/09513590009167667)

9 Spasovski G, Vanholder R, Allolio B, Annane D, Ball S, Bichet D, Decaux G, Fenske W, Hoorn EJ, Ichai C, et al. Clinical practice guideline on diagnosis and treatment of hyponatraemia. European Journal of Endocrinology 2014170 G1-G47. (https://doi.org/10.1530/ EJE-13-1020)

10 Putterman C, Almog Y, Caraco Y, Gross DJ \& Ben-Chetrit E. Inappropriate secretion of antidiuretic hormone in Sheehan's syndrome: a rare cause of postpartum hyponatremia. American Journal of Obstetrics and Gynecology 1991165 1330-1333.

11 Boulanger E, Pagniez D, Roueff S, Binaut R, Valat AS, Provost N, Leroy R, Codaccioni X \& Dequiedt P. Sheehan syndrome presenting as early post-partum hyponatraemia. Nephrology, Dialysis, Transplantation 199914 2714-2715.

12 Schrager S \& Sabo L. Sheehan syndrome: a rare complication of postpartum hemorrhage. Journal of the American Board of Family Practice 200114 389-391.

13 Lust K, McIntyre HD \& Morton A. Sheehan's syndrome - acute presentation with hyponatraemia and headache. Australian and New Zealand Journal of Obstetrics and Gynaecology 200141 348-351.

14 Bunch TJ, Dunn WF, Basu A \& Gosman RI. Hyponatremia and hypoglycemia in acute Sheehan's syndrome. Gynecological Endocrinology 200216 419-423.

15 Kaplun J, Fratila C, Ferenczi A, Yang WC, Lantos G, Fleckman AM \& Schubart UK. Sequential pituitary MR imaging in Sheehan syndrome: report of 2 cases. American Journal of Neuroradiology 200829 941-943. (https://doi.org/10.3174/ajnr.A1016)

16 Anfuso S, Patrelli TS, Soncini E, Chiodera P, Fadda GM \& Nardelli GB. A case report of Sheehan's syndrome with acute onset, hyponatremia and severe anemia. Acta Bio-Medica 200980 73-76.

17 Matsuzaki S, Endo M, Ueda Y, Mimura K, Kakigano A, EgawaTakata T, Kumasawa K, Yoshino K \& Kimura T. A case of acute Sheehan's syndrome and literature review: a rare but life-threatening complication of postpartum hemorrhage. BMC Pregnancy and Childbirth 201717 188. (https://doi.org/10.1186/s12884-017-1380-y)

Received in final form 21 February 2019

Accepted 22 February 2019 